\title{
PPAR y Agonist, Pioglitazone, Suppresses Melanoma Cancer in Mice by Inhibiting TLR4 Signaling
}

\author{
Nasim Dana ${ }^{1}$, Golnaz Vaseghi ${ }^{2,}{ }^{\text {, Shaghayegh Haghjooy Javanmard }}{ }^{1}$ \\ 1. Applied Physiology Research Center and Department of Physiology, Cardiovascular Research Institute, Isfahan \\ University of Medical sciences, Isfahan, Iran. ${ }^{2}$. Isfahan Cardiovascular Research Center, Cardiovascular Research Institute, \\ Isfahan University of Medical sciences, Isfahan, Iran
}

Received, August 9, 2019; Revised, August 19, 2019; Accepted September 1, 2019; Published, September 8, 2019.

\begin{abstract}
Background: Although previous studies demonstrated an anticancer effect for the ligands of peroxisome proliferator-activated receptor gamma (PPAR $\gamma$ ) through activation of its anti-inflammatory responses, nevertheless the anti-tumor mechanism of PPAR $\gamma$ has not been intensively investigated. One of the molecules involved in cancer progression is toll-like receptor 4 (TLR4). TLR4 signaling induces NF- $\mathrm{KB}$ activity which has a crucial role in cancer progression. In this study, we examined the cross-talk between PPAR $\gamma$ and TLR4 in the melanoma. Methods: B16F10 melanoma cells were cultured with or without LPS for $24 \mathrm{hr}$. The cells were subcutaneously injected to two groups of C57BL/6 mice. After the development of palpable tumors each group of animals were divide to four sub-groups and received pioglitazone in different dose ranges $(0,10,50,100 \mathrm{mg} / \mathrm{kg} / \mathrm{day})$ for 10 days. At the end of the study, the expression of Tlr4, Myd-88, Nf$k b 1$ genes was evaluated by qRT-PCR in different groups in mice tumor. The TLR-4 protein expression was evaluated by IHC. TNF- $\alpha$ level in mice tumor and serum were measured by ELISA kits. Tumor volume was measured with Vernier calipers. Results: We observed that activation of PPAR $\gamma$ by its agonist, pioglitazone, reduces tumor volume, Tlr-4, Myd-88, Nf-kbl mRNA expression, TLR4 protein expression and TNF- $\alpha$ production in melanoma tumor especially in groups that were injected with LPS -stimulated cells. Moreover, treatment of melanoma cells with pioglitazone showed that the inhibitory effects of pioglitazone on LPSinduced inflammatory responses were TLR4 dependent. Conclusion: The results indicate that pioglitazone, a PPAR $\gamma$ agonist, has a beneficial protective effect against melanoma via interfering with the TLR4-dependent signaling pathways.
\end{abstract}

\section{INTRODUCTION}

Toll-like receptors (TLRs) are major components of the innate immune system that recognize the conserved molecular structures of pathogens. There are many different cell types, ranging from epithelial to cancer cells that express TLRs (1). TLR4, one member of the TLRs family, could serve as important regulators in the development of a variety of cancers such as melanoma (2). TLR4 can be expressed by melanocytes, which are the main cell types that can become melanoma (3).

Previous findings suggest that over-expression of TLR4 by melanoma cells triggers an inflammatory response leading to tumor development (4). Previously we have shown that TLR4 Stimulation with a specific ligand( lipopolysaccharides: LPS) up regulates TLR-4 expression and activates $M y d-88$ and $N f-\kappa b$ in melanoma cells, that are three major factors in
TLR4 signaling pathway (5). The TLR signaling adaptor MyD88 plays an important role in tumor development. Overexpression of MyD88 was described in several tumors(6)and enhanced levels of MyD88 were associated with poor prognosis in some cancers(7-9). MyD88 is an essential adaptor molecule for induction of inflammatory cytokines through NF- $\mathrm{BB}$ triggered by TLR4(10).It is well established that LPS elicit inflammation via increasing levels of inflammatory cytokines (11). One of these cytokines, tumor necrosis factor- $\alpha$ (TNF- $\alpha$ ), has been reported to up regulate malignant melanoma invasion and migration in vitro (12). Peroxisome proliferator-activated receptor $\gamma$

Corresponding Author: Shaghayegh Haghjooy Javanmard .MD, Ph.D. Applied Physiology Research Center and Department of Physiology, Cardiovascular Research Institute, Isfahan University of Medical sciences, Isfahan, Iran.; Email: shaghayegh.haghjoo@gmail.com 
$(\operatorname{PPAR} \gamma)$ is a ligand-activated transcription factor, which is involved in melanoma cell proliferation (13), differentiation (14), apoptosis (15) and angiogenesis (16). Pioglitazone, a PPAR $\gamma$ agonist, significantly reduces inflammation through inhibition of NF- $\kappa$ B activity (17).

Recent evidence suggests that PPARs and TLRs signaling pathways have crosstalk in different diseases (18). The data reveal a regulatory feedback loop in which PPAR $\gamma$ represses NF-kB-mediated inflammatory signaling via TLR4 pathway (19). Recently, a study has shown that PPAR $\gamma$ activation with its specific agonist inhibits proliferation and enhances the apoptosis of esophageal cancer cells by affecting the TLR4- dependent MAPK pathway (20).

The studies provide evidence that PPAR $\gamma$ is implicated in the regulation of NF- $\kappa \mathrm{B}$ signaling by modulating TLR4 expression and TNF- $\alpha$ production (11,21-24). Recently we showed that fenofibrate, a PPAR $\alpha$ agonist; inhibit melanoma progression via interaction with TLR4 signaling pathway (25). Also our recent in vitro study has shown that pioglitazone inhibits TLR4 signal transduction pathway in melanoma cancer. As we know because the result of in vitro studies can be different from in vivo because of this, in vitro study is done in a controlled environment outside of a living organism and in vitro cell culture is a significantly different environment from that of a solid tumor.

So, we investigated the effects of PPAR $\gamma$ agonist pioglitazone on LPS mediated inflammation and the TLR4 signaling pathway involved in melanoma cancer in vivo to clarify the potential mechanisms of the anti-inflammatory action of pioglitazone.

\section{MATERIALS AND METHODS}

\section{Cell and Reagents}

The mouse melanoma cell line (B16F10) was obtained from the National Cell Bank of Iran (affiliated to Pasteur Institute, Tehran, Iran). Ultrapure LPS-EB from E. coli 0111: B4 was provided by InvivoGen (San Diego, CA, USA). Fetal bovine serum (FBS), Dulbecco's modified Eagle's medium (DMEM), penicillin and streptomycin were purchased from Gibco BRL (Carlsbad, CA, USA). Pioglitazone was produced by Sigma (St. Louis, MO, USA). Mouse TNF- $\alpha$ ELISA kit was purchased from eBioscience (San
Diego, CA, USA).TLR4 antibody (mouse monoclonal, sc-293072 HRP) was obtained from Santa Cruz Biotechnology (Santa Cruz Biotechnology, Dallas, TX, USA). For drug preparation, pioglitazone was dissolved in polyethylene glycol.

\section{Cell culture and Treatment}

The B16-F10 cells were grown in DMEM supplemented with normal FBS. One day before the cell injection to animals, cells were divided into two groups: one group was treated with LPS $(5 \mu \mathrm{g} / \mathrm{ml})$ for $24 \mathrm{hr}$ and the other group was treated with complete medium only. After incubation the cells were harvested and cell densities were measured using a haemocytometer after the addition of trypan blue.

\section{Animals}

C57BL/6 male mice ( $\mathrm{n}=48,6-8$ weeks old) were purchased from the Pasture Institute of Iran (Tehran). All mice were housed in standard cages with standard with $22-23^{\circ} \mathrm{C}$ temperature and $12 / 12$ dark/light cycle. They were maintained one week for acclimatization and then weighted once a week during the experiment. All the experiments were approved by the Ethical Committee of Isfahan University of Medical Sciences Isfahan, Iran (approval ID: IR. MUI . REC.1394.3.617).

After incubation of cells with or without LPS, tumors were induced into two groups (each one was 24 mice) and injecting $1 \times 10^{6}$ cells in $200 \mu \mathrm{L}$ of PBS subcutaneously in the right back flank (26). The day of cell transplantation was designated as day 0 .

Seven days later, each main group of mice with a palpable tumor were randomly distributed into four subgroups (each group contain six mice). Four LPS groups received an intraperitoneal injection of pioglitazone in different dose ranges $(0,10,50,100$ $\mathrm{mg} / \mathrm{kg} /$ day) for 10 days. Their control group received only vehicle (normal saline \&Polyethylene glycol). The other four groups that were injected with untreated cells were received the same pioglitazone treatment and their control group was administrated vehicle for 10 days. All eight groups of animals were euthanized at the study endpoint (20 days) and the tumors were excised for further examination.

\section{Tumor volume}

The tumor volume was calculated by determining the length and width of the tumor as measured using 
Vernier calipers. Tumor volumes based on caliper measurements were calculated by the modified ellipsoidal formula(27).

$$
\text { Tumor volume }=1 / 2\left(\text { length } \times \text { width }^{2}\right)
$$

\section{Total RNA isolation}

Tumor tissues obtained from each mouse were frozen in liquid nitrogen for RNA extraction. Tumor tissues were homogenized in Lysis Buffer (Thermo Scientific) using Micro Smash MS-100R (Tomy Digital Microbiology Co Ltd, Tokyo, Japan) and RNA was extracted by using total RNA Extraction Kit GeneJet RNA Purification kit (Thermo Scientific, (EU) Lithuania) according to the manufacturer's instructions.

The concentrations and quality of RNA were determined by a spectrophotometer (BioTek Instruments, Epoch, USA) and gel electrophoresis. RNA samples were treated with RNase free DNase (Qiagen, USA) to eliminate the genomic DNA. Total RNA from each sample was reversetranscribed into cDNA by using a RevertAid First Strand cDNA Synthesis Kit (Fermentas, Vilnius, Lithuania).

\section{Quantitative reverse transcriptase polymerase chain reaction (qRT-PCR)}

Real-time qRT-PCR was performed for the detection of the mRNA expressions of Tlr-4, Myd88 , and $N f-k b 1$. The primer sequences for $T l r-4$, $M y d-88, N f-k b 1$, and beta-actin were designed from the sequence list of GeneBank database (National Centre for Biotechnology Information, NCBI) using Beacon designer 8 software and then blasted against GeneBank database sequences (Tlr-4, 5'AGTGGCTGGATTTATCCAGGTGTG-

3'(forward) and 5'-
TTGAGAGGTGGTGTAAGCCATGCC3'(reverse) ; Myd-88, 5'AAGTCTAGGAAGGCCCCAAA-3' (forward) and 5'-CTGGGGAGAAAACAGCTGAG-3' (reverse) ; $N f-k b l, \quad 5 '-\quad$ ACACGAGGCTACAACTCTGC$3^{\prime}$ (forward) and $5^{\prime}$ GGTACCCCCAGAGACCTCAT-3'(reverse) ; $\beta$ actin, 5'- GCTGTATTCCCCTCCATCGTG 3 '(forward) and 5'- CACGGT TGGCCT TAGGGTTCAG -3'(reverse)).

Real-time RT-PCR was carried out by the Maxima SYBR Green Rox qPCR master mix kit (Fermentas, Vilnius, Lithuania). Real-time PCR reactions were performed using Corbett machine,
Rotorgene 6000 (Australia). The PCR amplification conditions consisted of $15 \mathrm{~min}$ at $95^{\circ} \mathrm{C}$ followed by 40 cycles of the denaturation step at $95^{\circ} \mathrm{C}$ for $15 \mathrm{~s}$ and annealing and extension for $1 \mathrm{~min}$ at $60{ }^{\circ} \mathrm{C}$.

The expression level of each target gene normalized with respect to the expression of housekeeping $\beta$-actin gene was calculated as $2^{-}$ ${ }^{\Delta \Delta \mathrm{Ct}}$. These experiments were carried out in triplicate and repeated independently at two times.

\section{Immunohistochemistry}

Tumor tissues were fixed in $10 \%$ formalin, embedded in paraffin, sectioned and immunohistochemistry performed as described previously(25) .Finally, images were captured using the Leica microscope equipped with a Leica camera (DFC450 C). The TLR-4 protein expression was evaluated by ImageJ software.

\section{Enzyme-linked immunosorbent assay (ELISA)}

For determination of TNF- $\alpha$ level in tumor lysate, snap frozen tumors were lysed using RIPA buffer containing a protein inhibitor cocktail (Calbiochem, San Diego, CA). Tissue lysates were cold centrifuged at $12,000 \mathrm{rmp}$ for $30 \mathrm{~min}$ and then the supernatants were collected. Protein concentration was determined by the Bradford method using BioRad Protein Assay Dye and microtiter plate reader (ELX 800-BioTek-USA). Finally level of TNF- $\alpha$ was measured by Elisa kits in tumor lysate.

To detect the effect of pioglitazone on TNF- $\alpha$ level in mouse serum, concentrations of TNF- $\alpha$ was determined in serum aliquots from animals of the different groups with commercially TNF- $\alpha$ Detection ELISA Kits (Mouse TNF- $\alpha$ Instant ELISA and mouse) according to the manufacturer's instruction.

\section{STATISTICAL ANALYSIS}

Data were expressed as means \pm S.E.M. Differences among more than two groups were determined either by one-way ANOVA followed by post hoc Dunns multiplecomparison test. Differences between two groups were tested by t-tests. The results analyzed for gene expression with one sample t-test between the treated and the control groups and with one-way ANOVA between the other groups followed by Tukey's test. A value of $\mathrm{P}$ $<0.05$ was considered statistically. Statistical analysis was performed using the SPSS 19 software. 


\section{RESULTS}

\section{Pioglitazone inhibits the growth of subcutaneous B16F10 tumors}

At first, to determine the antineoplastic effect of pioglitazone in vivo, male $\mathrm{C} 57 \mathrm{BL} / 6$ mice were used. As soon as tumor became palpable, about 7 days after cell injection, mice received subcutaneous injection of vehicle or pioglitazone $(0$, $10,50,100 \mathrm{mg} / \mathrm{kg} /$ day) and continued on diets for 10 more days. Untreated control mice rapidly developed visible tumors and dramatic growth was observed throughout the course of the study. In contrast, treatment of mice with pioglitazone with $50 \quad(\mathrm{p}<0.05)$ and $\quad 100(\mathrm{P}<0.01) \quad \mathrm{mg} / \mathrm{kg} /$ day concentration significantly attenuated the ability of cells to develop tumors. These data clearly demonstrate that pioglitazone has anti-melanoma activity in vivo.

To examine the inhibitory effect of pioglitazone on LPS-stimulated tumor growth, before cell injection to the mice, B16f10 cells were pretreated with $5 \mu \mathrm{g} / \mathrm{ml}$ of LPS for 24 . As demonstrated in Figure 1, administration of pioglitazone led to a significant reduction in tumor volume in 10 and $50 \mathrm{mg} / \mathrm{kg} /$ day doses $(\mathrm{P}<0.05)$ compared to the mice that received only LPS treated cells.
Pioglitazone decreases expressions of Tlr4, Myd88 , and $N f-k b 1$ in mice tumor

To assess the effect of LPS on TLR4 signaling in melanoma tumor, we measured the amount of Tlr4, $M y d-88$ and $N f-k b 1$ mRNA expression in mice that were injected with the pre-treated B16F10 cells with or without LPS for $24 \mathrm{~h}$. Treatment of cells with LPS before injection to mice significantly elevated the levels of Tlr4 $(\mathrm{P}<0.001), M y d-88$ $(\mathrm{P}<0.01)$ and $N f-k b 1(P<0.001)$ mRNAs in tumor tissue. We also determined whether pioglitazone alone has effects on Tlr4, Myd-88 and $N f$ $k b l$ expression in mice tumor tissue. As shown in figure 2A, Tlr4 expression was significantly decreased by $10(\mathrm{P}<0.05), 50$ and $100 \mathrm{mg} / \mathrm{kg} /$ day $(\mathrm{P}<0.01)$ doses of pioglitazone. $M y d-88$ expression at all of the doses $(\mathrm{P}<0.01)$ and the expression of $N f-k b$ was reduced significantly at doses of 10 $(P<0.05), 50(\mathrm{P}<0.01)$ and $100 \mathrm{mg} / \mathrm{kg} /$ day $(\mathrm{P}<0.01)$. In the other groups that were injected with LPS treated cells, pioglitazone injection significantly reduced the expression of Tlr4, Myd-88 and Nf$k b$ in all doses in comparing with their control group (Figure 2B).

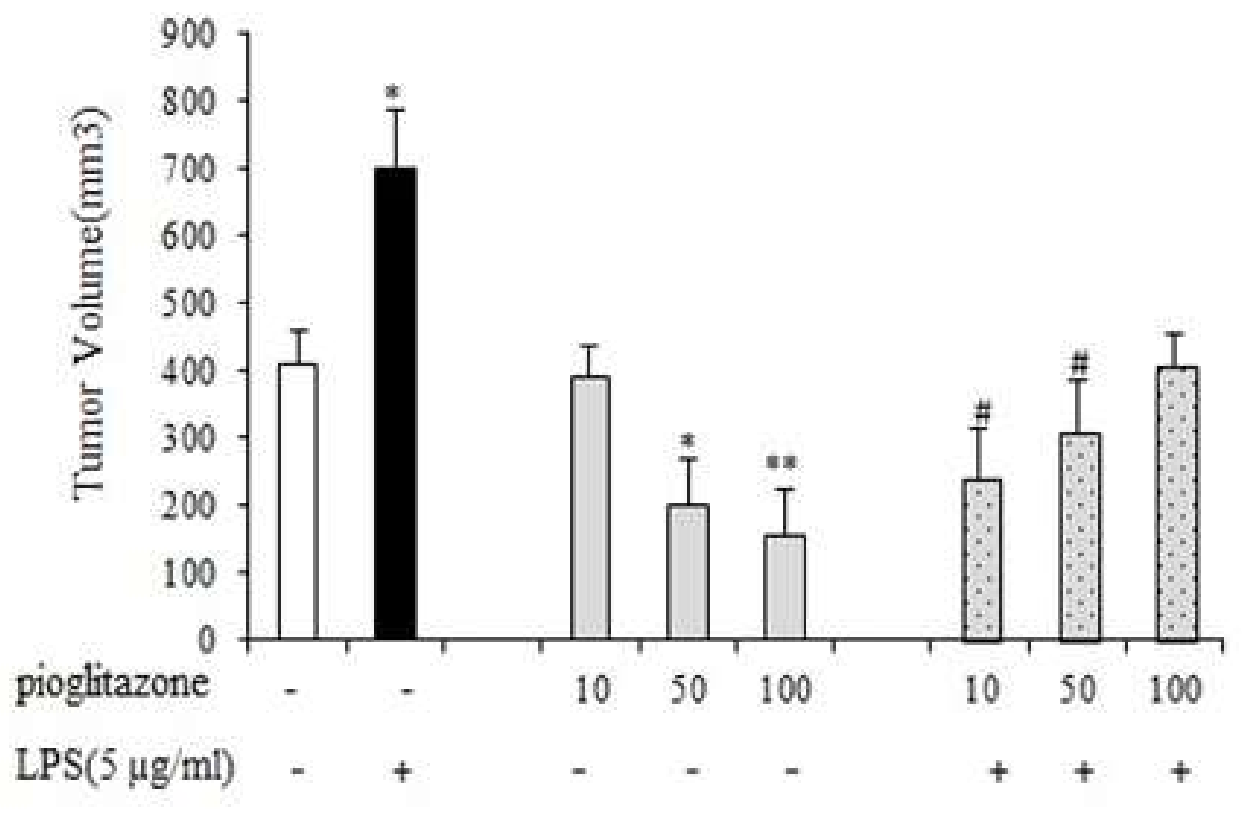

Figure 1. Mean melanoma tumors size in different groups. Mice were injected with LPS treated or untreated cells. Tumor bearing animals were treated for 10 days with different concentration of pioglitazone. $* \mathrm{P}<0.05, * * \mathrm{P}<0.01$, in comparison with control group and $\# \mathrm{P}<0.01$ compare LPS group. Each graph has been represented as Mean $\pm \mathrm{SEM}$. 


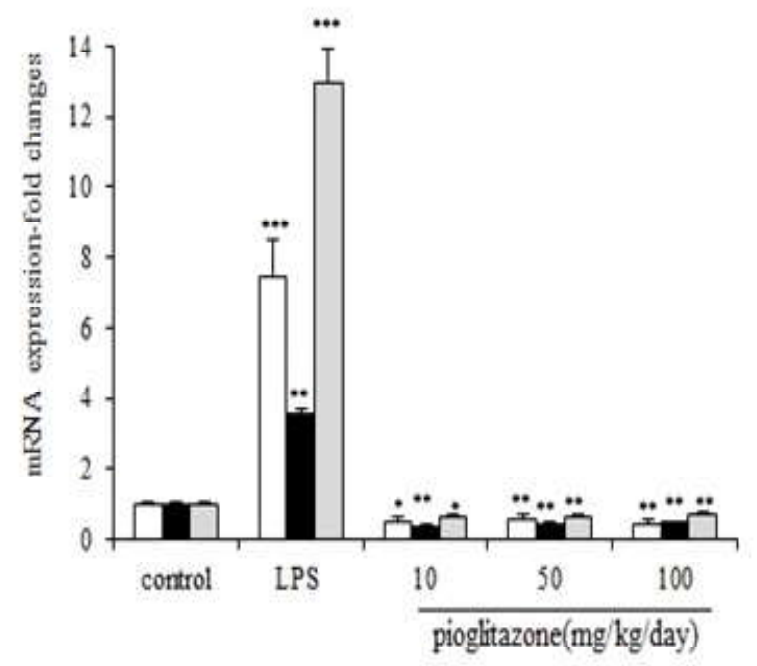

A

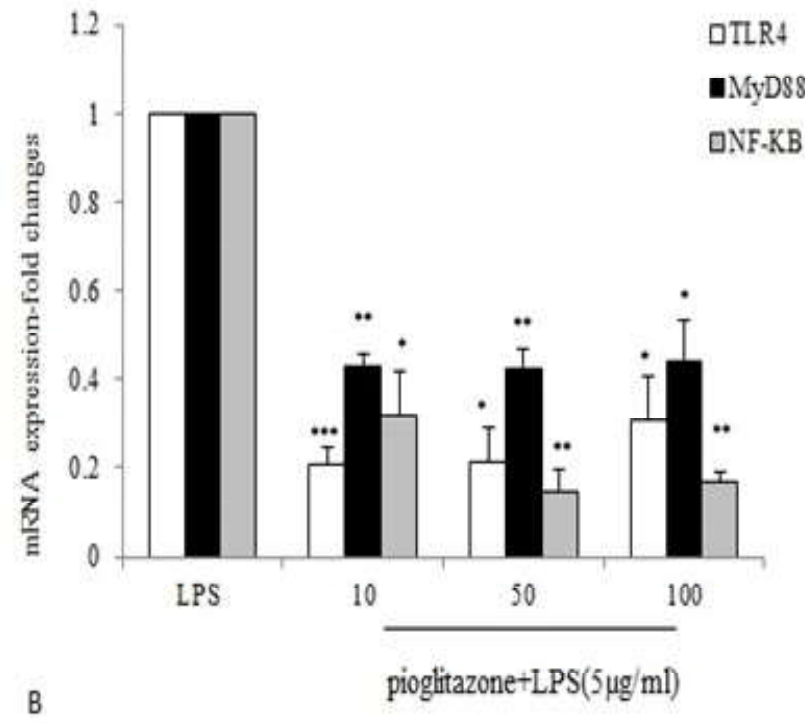

Figure 2. Effect of LPS and pioglitazone on the gene expression of Tlr4, Myd-88, and Nf-kb in melanoma tumors. A) Experimental groups were injected by B16F10 cells and then administered pioglitazone as described in the materials and methods section. B) Mice were injected with LPS treated B16F10 cells. Following the development of tumors mice were injected with different concentration of pioglitazone. The mRNA level of Tlr4, Myd-88, and Nf-kb was determined by QRT-PCR. Fold changes relative to control are presented as Mean \pm SEM. ${ }^{*} \mathrm{P}<0.05, * * \mathrm{P}<0.01$, and $* * * \mathrm{P}<0.001$ compared with control group.

\section{Pioglitazone decreases TLR4 protein expression in mice melanoma}

All the samples, including control, LPS and pioglitazone 50 and $100(\mathrm{mg} / \mathrm{kg} /$ day $)$, groups with or without LPS, were positive for TLR-4 protein expression. As shown in figure 3 compared with the control group, the TLR-4 expression was significantly increased in the LPS group $(\mathrm{P}<0.001)$. We found reduced TLR-4 protein expression in the pioglitazone group, but it was not significant when compared with the control group $(\mathrm{P}<0.05)$. Interestingly, we found reduced TLR-4 protein expression in the group that received LPS and pioglitazone 50 and $100(\mathrm{mg} / \mathrm{kg} /$ day $)$ compared with the LPS group $(\mathrm{P}<0.001)$.

\section{Pioglitazone inhibits TNF- $\alpha$ production in mice tumor lysate}

To examine the effect of LPS on TNF- $\alpha$ concentration in serum and tumor lysate its level was determined by Elisa kit. Our results have shown that the mice group that was injected with LPS treated cells, the amounts of TNF- $\alpha$ in tumor tissue was significantly higher than the control group (Figure 4A).

The results illustrated that pioglitazone in each mice with or without LPS-treated cells had no effect on TNF- $\alpha$ concentration in mice serum compared to control group (Figure 4B).

\section{DISCUSSION}

The present study provided evidence that pioglitazone reduced melanoma progression by suppressing the TLR4 signaling pathway and inflammatory cytokine.

Various studies strongly suggest that PPAR $\gamma$ agonists in addition to the anti-diabetic effect, can induce cell growth arrest, apoptosis, and terminal differentiation in many human malignant tumors (28).

PPAR family plays a regulatory role in cell cycle and growth (29). Activation of PPAR agonists can lead to inhibition of tumorgenesis and provide new insights to cancer therapy $(28,30,31)$.

Rosiglitazone, a PPAR $\gamma$ agonist was shown to inhibit hepatocellular carcinoma (32), and gastric cancer cell growth (33). Also, troglitazone the other PPAR $\gamma$ agonist has the same effect on prostate cancer cells (34). PPAR agonists exert this regulatory effect via regulating the expression and blocking the oncogenic proteins (20). In our study, we found that PPAR $\gamma$ agonist 
significantly reduced tumor size and melanoma cell proliferation.

Activation of TLR4 by LPS significantly enhanced the survival of melanoma cells while TLR4 inhibition led to the death of melanoma cells (35). In the present study, we also observed that LPS increased expression levels of Tlr4, Myd-88, and $N f-\kappa b l$, whereas pioglitazone reversed this effect. So we conclude that PPAR $\gamma$ agonist inhibited the progression of melanoma cells via blocking the TLR4 pathway.

In general, our result suggested that activation of PPAR $\gamma$ suppressed proliferation and induced apoptosis of melanoma cells via inhibiting TLR4dependent NF-kb pathway.

Several studies are warranted to investigate PPAR $\gamma$ expression in skin cancer and the mechanisms by which this receptor affect skin carcinogenesis, such as, proliferation, apoptosis , inflammation and angiogenesis $(16,36)$. The antiproliferative activity of PPAR $\gamma$ agonists opens up interesting new perspectives for melanoma treatment. Freudlsperger et al. have been shown a significant inhibitory effect of glitazones on the proliferation of human melanoma cells in vitro (37).
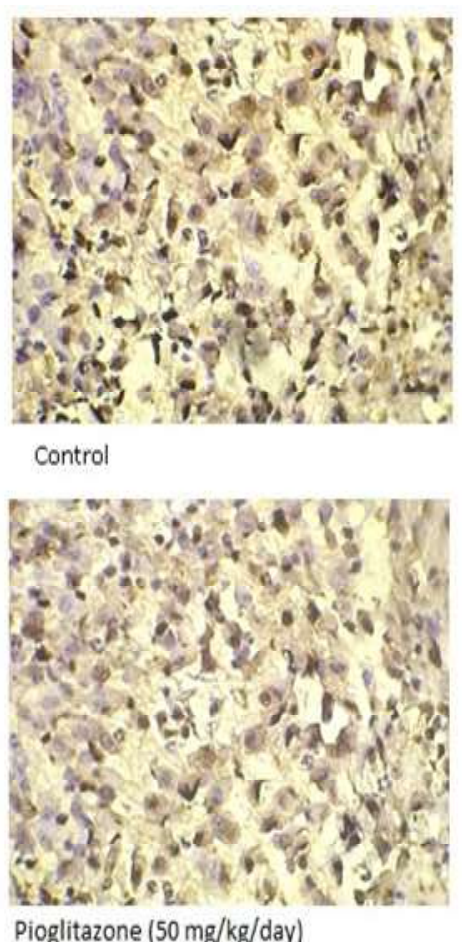

Pioglitazone $(50 \mathrm{mg} / \mathrm{kg} /$ day)

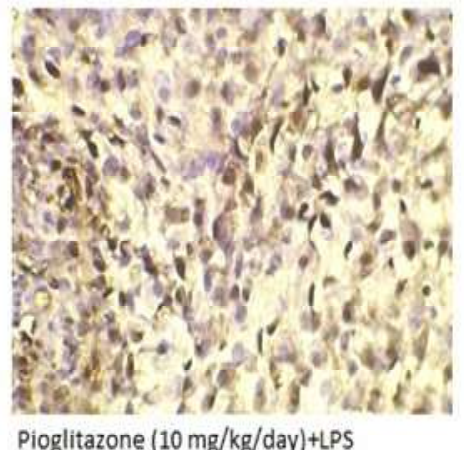

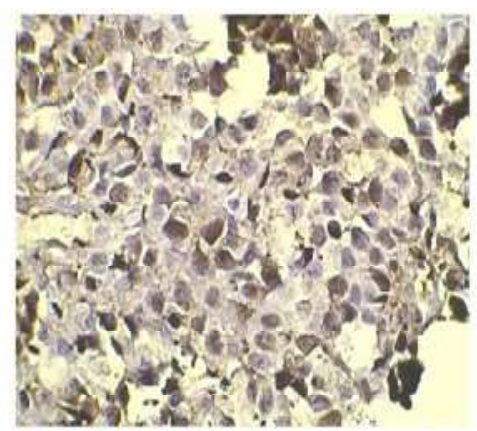

LPS $(5 \mu \mathrm{g} / \mathrm{ml})$

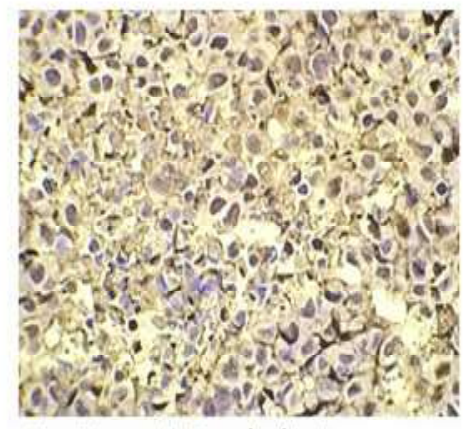

Pioglitazone $(100 \mathrm{mg} / \mathrm{kg} /$ day $)$

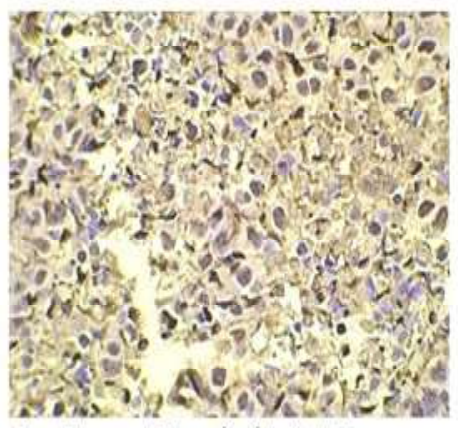

Pioglitazone $(50 \mathrm{mg} / \mathrm{kg} /$ day $)+$ LPS

Figure 3. Immunohistochemical evaluation of TLR4 . A) TLR-4, IHC quantifications relative to respective negative control in melanoma tumors. B) Pictures are representative fields of tumor staining for each tumor [original magnification, $\times 400$ ]. $* * * \mathrm{P}<.001$, in comparison with control group, \#\#\#P $<.001$, compare LPS group. 


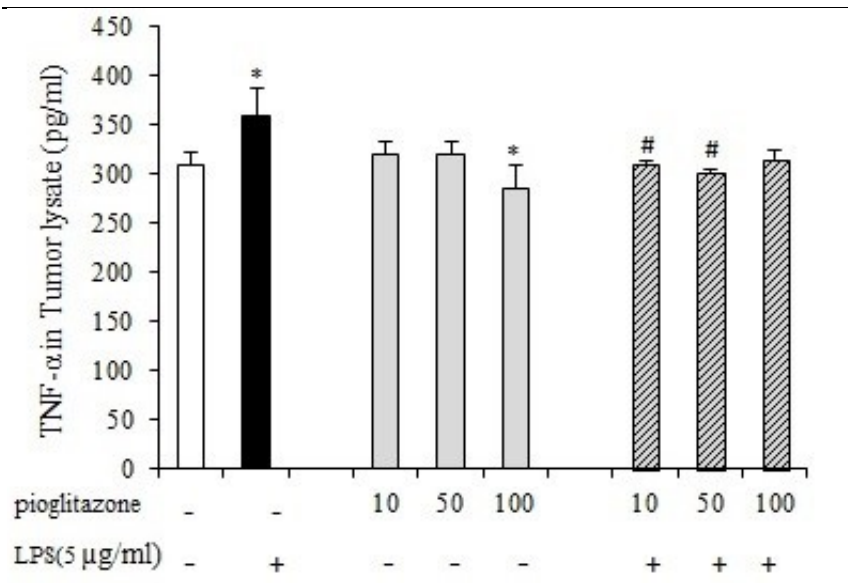

A

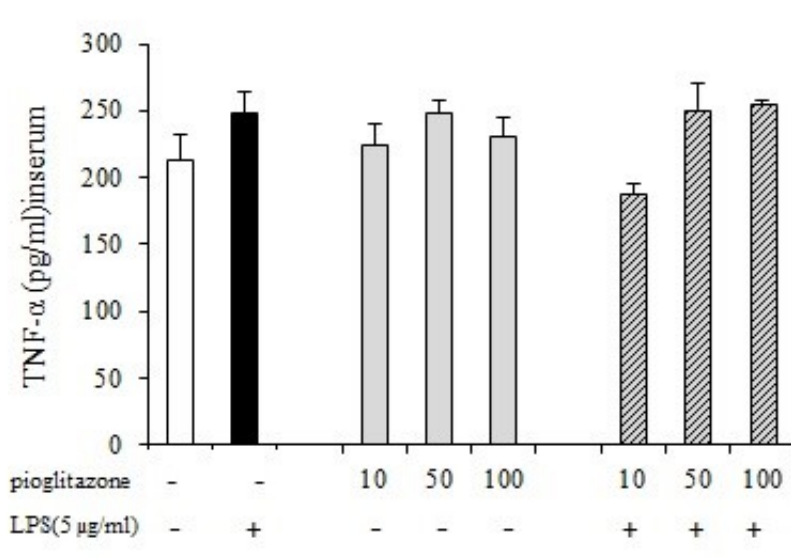

B

Figure 4. Effect of pioglitazone on TNF- $\alpha$ production in mice serum and tumor tissue lysate. $* \mathrm{P}<0.05$, in comparison with control group and $\# \mathrm{P}<0.05$ compare LPS group. Each graph has been represented as Mean $\pm \mathrm{SEM}$.

For the first time, in the present study, we show that pioglitazone can significantly decrease $T l r 4$, $M y d-88$ and $N f-\kappa b l$ gene expression in vivo with or without LPS stimulation. Also treatment of mice with pioglitazone resulted in a significant reduction in the TLR4 protein expression in tumor lysate in a group that received LPS stimulated cells. It has been known that TLR 4 expression in many tumors or cell lines was up-regulated (38). Previous studies demonstrated that pioglitazone attenuated AngiotensinII-induced inflammatory response in cardiac fibroblast cells through inhibition of the TLR4 signaling pathway (39) and the other PPAR $\gamma$ agonist, roziglirazone suppressed the expression of Tlr 4 mRNA and protein in alveolar macrophages (40), which are consistent with our study. A recent study highlighted that LPS increased expression levels of Tlr4, Myd-88, whereas PPAR $\gamma$ agonist, roziglitazone resisted this effect in esophageal cancer cells(20). It has been shown that PPAR $\gamma$ 15d-PGJ2 regulates Tlr4 mRNA and protein expression in HT-29 cells(41). Also, it has been shown that Hypaphorine, an indole alkaloid from Erythrina velutina, protects HMEC-1 cells against LPS-induced inflammation by inhibiting PI3K/Akt/mTOR signaling pathways, followed by the interactive modulation of TLR4 with PPAR$\gamma(42)$. 6-Shogaol, a pungent agent isolated from Zingiber officinale Roscoe, has been known to have anti-tumor and anti-inflammatory effects.It has been shown that 6-Shogaol could increase the expression of PPAR- $\gamma$. It can inhibit LPS-induced inflammation BV2 microglia cells by activating PPAR- $\gamma(43)$.Similarly activation of PPAR- $\gamma$ by nuciferine, a bioactive component extracted from the lotus leaf, can inhibit the LPS-induced inflammation in BV2 cells(44).

In the present study, we also observed that LPS increased the amount of TNF- $\alpha$ in tumor lysate but not in mice serum and pioglitazone can inhibit LPS effect on TNF- $\alpha$ production. It has been shown the role of PPAR $\gamma$ in the regulation of NF-kB signaling by modulating Tlr4 expression and TNF- $\alpha$ production in LPS stimulated monocyte Leukemia cells (45).

The other PPAR $\gamma$ agonists, Glitazones, have demonstrated the capacity to diminish inflammatory cytokine production, most notably, that of tumor necrosis factor- $\alpha$. Several lines of evidence indicate significant thiazolidinedione mediated antitumor activity.

These results indicated that pioglitazone may counteract LPS-stimulated inflammation via the blockade of TLR4. Perviously in our in vitro study ,we evaluated the effects of TLR4 inhibitor in combination with pioglitazone on the production of TNF- $\alpha$ in B16F10 cells treated with LPS or nothing. We observed that pioglitazone and TLR4 inhibitor, CLI-095, co-treatment synergistically inhibited LPS-induced production of TNF- $\alpha$. This indicates the inhibitory effect of pioglitazone on the TLR4 signaling. Therefore, in terms of in vivo conditions, pioglitazone has the same effect on this pathway.

In summary, these findings provide the evidence for beneficial effects of PPAR $\gamma$ activator pioglitazone to counter-regulate melanoma cancer by affecting on TLR4 signaling pathway. More importantly, the anti-inflammatory action of 
pioglitazone via interfering with the TLR4dependent signaling pathway (TLR4/MyD-88/NF$\mathrm{kB}$ ) work against melanoma.

\section{CONFLICT OF INTEREST}

None.

\section{ACKNOWLEDGMENT}

This article is driven from a Ph.D. thesis promoted at Isfahan University of Medical Sciences with a grant number of No. 394617 and under ethical approval number of IR. MUI (REC .1394.3.617).This work was financially supported by Iran National Science Foundation (INSF) [grantnumber 95844116].

\section{REFERENCES}

1. Shcheblyakov D V, Logunov DY, Tukhvatulin AI, Shmarov MM, Naroditsky BS, Gintsburg AL. TollLike Receptors (TLRs): The Role in Tumor Progression. Acta naturae . $2010 \mathrm{Jul} ; 2(3): 21-9$.

2. Shi M, Chen X, Ye K, Yao Y, Li Y. Application potential of toll-like receptors in cancer immunotherapy: Systematic review. Medicine . 2016 Jun;95(25):e3951.

doi: 10.1097/MD.0000000000003951

3. Burns EM, Yusuf N. Toll-like receptors and skin cancer. Frontiers in immunology . 2014;5:135. doi: 10.3389/fimmu.2014.00135.

4. Mittal D, Saccheri F, Vénéreau E, Pusterla T, Bianchi ME, Rescigno M. TLR4-mediated skin carcinogenesis is dependent on immune and radioresistant cells. The EMBO journal . $2010 \mathrm{Jul}$ 7;29(13):2242-52. doi: 10.1038/emboj.2010.94

5. Dana N, Javanmard SH, Vaseghi G. Effect of lipopolysaccharide on toll-like receptor-4 signals in mouse cancer cells. Bratislavske lekarske listy . 2017;118(10):598-601.

doi: 10.4149/BLL 2017115

6. Je EM, Kim SS, Yoo NJ, Lee SH. Mutational and expressional analyses of MYD88 gene in common solid cancers. Tumori . 2012;98(5):663-9. doi:10.1700/1190.13209

7. Liang B, Chen R, Wang T, Cao L, Liu Y, Yin F, et al. Myeloid Differentiation Factor 88 Promotes Growth and Metastasis of Human Hepatocellular Carcinoma. Clinical Cancer Research . 2013 Jun 1;19(11):2905-16. doi:10.1158/1078-0432.CCR-121245

8. Wang EL, Qian ZR, Nakasono M, Tanahashi T, Yoshimoto K, Bando Y, et al. High expression of Toll-like receptor 4/myeloid differentiation factor 88 signals correlates with poor prognosis in colorectal cancer. British Journal of Cancer . 2010 Mar 9;102(5):908-15.

9. Zhu Y, Huang J-M, Zhang G-N, Zha X, Deng B-F. Prognostic significance of MyD88 expression by human epithelial ovarian carcinoma cells. Journal of translational medicine . 2012 Apr 25;10:77. doi: 10.1186/1479-5876-10-77

10. Sugiyama K, Muroi M, Kinoshita M, Hamada O, Minai Y, Sugita-Konishi Y, et al. NF- $\mathrm{KB}$ activation via MyD88-dependent Toll-like receptor signaling is inhibited by trichothecene mycotoxin deoxynivalenol. The Journal of toxicological sciences . 2016 Apr;41(2):273-9. doi: $10.2131 /$ jts. 41.273

11. Ji Y, Liu J, Wang Z, Li Z. PPAR $\gamma$ agonist rosiglitazone ameliorates LPS-induced inflammation in vascular smooth muscle cells via the TLR4/TRIF/IRF3/IP-10 signaling pathway. Cytokine . 2011 Sep;55(3):409-19. doi: 10.1016/j.cyto.2011.05.020

12. Katerinaki E, Evans GS, Lorigan PC, MacNeil S. TNF-alpha increases human melanoma cell invasion and migration in vitro: the role of proteolytic enzymes. British journal of cancer . 2003 Sep 15;89(6):1123-9. doi: 10.1038/sj.bjc.6601257

13. Mössner R, Schulz U, Krüger U, Middel P, Schinner $\mathrm{S}$, Füzesi L, et al. Agonists of peroxisome proliferator-activated receptor gamma inhibit cell growth in malignant melanoma. The Journal of investigative dermatology . 2002 Sep;119(3):57682. doi: 10.1046/j.1523-1747.2002.01861.x

14. Grabacka M, Placha W, Urbanska K, Laidler P, Płonka PM, Reiss K. PPAR gamma regulates MITF and beta-catenin expression and promotes a differentiated phenotype in mouse melanoma S91. Pigment cell \& melanoma research . 2008 Jun;21(3):388-96. doi: $10.1111 /$ j.1755148X.2008.00460.x

15. Costa V, Foti D, Paonessa F, Chiefari E, Palaia L, Brunetti $G$, et al. The insulin receptor: a new anticancer target for peroxisome proliferatoractivated receptor-gamma (PPARgamma) and thiazolidinedione-PPARgamma agonists. Endocrinerelated cancer . 2008 Mar;15(1):325-35. doi: 10.1677/ERC-07-0226

16. Dana N, Javanmard SH, Rafiee L. Role of peroxisome proliferator-activated receptor alpha and gamma in antiangiogenic effect of pomegranate peel extract. Iranian journal of basic medical sciences . 2016 Jan;19(1):106-10.

17. Kaplan J, Nowell M, Chima R, Zingarelli B. Pioglitazone reduces inflammation through inhibition of NF- $\mathrm{kB}$ in polymicrobial sepsis. Innate immunity . 2014 Jul;20(5):519-28. doi: 10.1177/1753425913501565

18. Dana N, Vaseghi G, Haghjooy Javanmard S. 
Crosstalk between Peroxisome Proliferator-

Activated Receptors and Toll-Like Receptors: A Systematic Review. Advanced pharmaceutical bulletin . 2019 Feb;9(1):12-21. doi: 10.15171/apb.2019.003

19. Necela BM, Su W, Thompson EA. Toll-like receptor 4 mediates cross-talk between peroxisome proliferator-activated receptor gamma and nuclear factor-kappaB in macrophages. Immunology . 2008 Nov;125(3):344-58. doi: 10.1111/j.13652567.2008.02849.x

20. Wu K, Yang Y, Liu D, Qi Y, Zhang C, Zhao J, et al. Activation of PPAR $\gamma$ suppresses proliferation and induces apoptosis of esophageal cancer cells by inhibiting TLR4-dependent MAPK pathway. Oncotarget . 2016 Jul 12;7(28):44572-82. doi: 10.18632/oncotarget. 10067

21. Dubuquoy L, Jansson EA, Deeb S, Rakotobe S, Karoui M, Colombel J-F, et al. Impaired expression of peroxisome proliferator-activated receptor gamma in ulcerative colitis. Gastroenterology . 2003 May;124(5):1265-76.

22. Dasu MR, Park S, Devaraj S, Jialal I. Pioglitazone inhibits Toll-like receptor expression and activity in human monocytes and db/db mice. Endocrinology . 2009 Aug;150(8):3457-64. doi: 10.1210/en.20081757

23. Chistyakov D V., Aleshin S, Sergeeva MG, Reiser $\mathrm{G}$. Regulation of peroxisome proliferator-activated receptor $\beta / \delta$ expression and activity levels by tolllike receptor agonists and MAP kinase inhibitors in rat astrocytes. Journal of Neurochemistry . 2014 Aug;130(4):563-74. doi: 10.1111/jnc.12757

24. Appel S, Mirakaj V, Bringmann A, Weck MM, Grünebach F, Brossart P. PPAR-gamma agonists inhibit toll-like receptor-mediated activation of dendritic cells via the MAP kinase and NF-kappaB pathways. Blood . 2005 Dec 1;106(12):3888-94. doi: 10.1182/blood-2004-12-4709

25. Dana N, Haghjooy Javanmard S, Vaseghi G. The effect of fenofibrate, a PPAR $\alpha$ activator on toll-like receptor-4 signal transduction in melanoma both in vitro and in vivo. Clinical \& translational oncology : official publication of the Federation of Spanish Oncology Societies and of the National Cancer Institute of Mexico . 2019 Jun 7. doi: 10.1007/s12094-019-02150-7

26. Overwijk WW, Restifo NP. B16 as a mouse model for human melanoma. Current protocols in immunology . 2001 May;Chapter 20:Unit 20.1. doi: 10.1002/0471142735.im2001s39

27. Jensen MM, Jørgensen JT, Binderup T, Kjaer A. Tumor volume in subcutaneous mouse xenografts measured by microCT is more accurate and reproducible than determined by $18 \mathrm{~F}-\mathrm{FDG}-$ microPET or external caliper. BMC medical imaging . 2008 Oct 16;8:16. doi: 10.1186/1471-

\section{2-8-16}

28. Bundscherer A, Reichle A, Hafner C, Meyer S, Vogt T. Targeting the Tumor Stroma with Peroxisome Proliferator Activated Receptor (PPAR) Agonists. Anti-Cancer Agents in Medicinal Chemistry . 2009 Sep 1;9(7):816-21. doi: 10.2174/187152009789056912

29. Skrypnyk N, Chen X, Hu W, Su Y, Mont S, Yang S, et al. PPAR $\alpha$ activation can help prevent and treat non-small cell lung cancer. Cancer research . 2014 Jan 15;74(2):621-31.

30. Zhu B, Ferry CH, Blazanin N, Bility MT, Khozoie $\mathrm{C}$, Kang B-H, et al. PPAR $\beta / \delta$ promotes HRASinduced senescence and tumor suppression by potentiating $\mathrm{p}-\mathrm{ERK}$ and repressing $\mathrm{p}-\mathrm{AKT}$ signaling. Oncogene . 2014 Nov 13;33(46):5348-59. doi: 10.1038/onc.2013.477.

31. Tachibana K, Yamasaki D, Ishimoto K, Doi T. The Role of PPARs in Cancer. PPAR Research. 2008;2008:1-15. doi: 10.1155/2008/102737

32. Cao L-Q, Shao Z-L, Liang H-H, Zhang D-W, Yang $\mathrm{X}-\mathrm{W}$, Jiang $\mathrm{X}-\mathrm{F}$, et al. Activation of peroxisome proliferator-activated receptor- $\gamma$ (PPAR $\gamma$ ) inhibits hepatoma cell growth via downregulation of SEPT2 expression. Cancer letters . 2015 Apr 1;359(1):12735. doi: 10.1016/j.canlet.2015.01.004

33. Cho S-J, Kook M-C, Lee JH, Shin J-Y, Park J, Bae $\mathrm{Y}-\mathrm{K}$, et al. Peroxisome proliferator-activated receptor $\gamma$ upregulates galectin-9 and predicts prognosis in intestinal-type gastric cancer. International journal of cancer . 2015 Feb 15;136(4):810-20. doi: 10.1002/ijc.29056

34. Bolden A, Bernard L, Jones D, Akinyeke T, Stewart L V. The PPAR Gamma Agonist Troglitazone Regulates Erk 1/2 Phosphorylation via a PPAR $\gamma$ Independent, MEK-Dependent Pathway in Human Prostate Cancer Cells. PPAR research 2012;2012:929052. doi: 10.1155/2012/929052

35. Chen X, Chang L, Qu Y, Liang J, Jin W, Xia X. Tea polyphenols inhibit the proliferation, migration, and invasion of melanoma cells through the downregulation of TLR4. International journal of immunopathology and pharmacology . 2018;32:394632017739531. doi: 10.1177/0394632017739531

36. Sertznig P, Reichrath J. Peroxisome proliferatoractivated receptors (PPARs) in dermatology: Challenge and promise. Dermato-endocrinology . 2011 Jul;3(3):130-5. doi: 10.4161/derm.3.3.15025

37. Freudlsperger C, Schumacher U, Reinert S, Hoffmann J. The Critical Role of PPARgamma in Human Malignant Melanoma. PPAR research . 2008;2008:503797. doi: 10.1155/2008/503797

38. Andreani V, Gatti G, Simonella L, Rivero V, Maccioni M. Activation of Toll-like receptor 4 on tumor cells in vitro inhibits subsequent tumor growth in vivo. Cancer research . 2007 Nov 
1;67(21):10519-27. doi: 10.1158/0008-5472.CAN07-0079

39. Dengfeng G, Meng Z, Liu Z, Dong X, Dengfeng G. GW25-e5248 PPAR $\gamma$ agonist Pioglitazone Suppresses AngII-induced Inflammation in Cardiac Fibroblast Cells via TLR4-depended Signaling Pathway. Journal of the American College of Cardiology . 2014 Oct;64(16):C13-4. doi: 10.1016/j.jacc.2014.06.071

40. Yin Y, Hou G, Li E, Wang Q, Kang J. PPAR $\gamma$ agonists regulate tobacco smoke-induced Toll like receptor 4 expression in alveolar macrophages. Respiratory research . 2014 Mar 11;15:28. doi: 10.1186/1465-9921-15-28

41. Eun CS, Han DS, Lee SH, Paik CH, Chung YW, Lee J, et al. Attenuation of colonic inflammation by PPARgamma in intestinal epithelial cells: effect on Toll-like receptor pathway. Digestive diseases and sciences . 2006 Apr;51(4):693-7. doi: 10.1007/s10620-006-3193-0

42. Sun H, Zhu X, Cai W, Qiu L. Hypaphorine
Attenuates Lipopolysaccharide-Induced Endothelial Inflammation via Regulation of TLR4 and PPAR- $\gamma$ Dependent on PI3K/Akt/mTOR Signal Pathway. International Journal of Molecular Sciences . 2017 Apr 17;18(4):844. doi: 10.3390/ijms 18040844

43. Han Q, Yuan Q, Meng X, Huo J, Bao Y, Xie G. 6Shogaol attenuates LPS-induced inflammation in BV2 microglia cells by activating PPAR- $\gamma$. Oncotarget . 2017 Jun 27;8(26):42001-6. doi: 10.18632/oncotarget.16719

44. Zhang L, Gao J, Tang P, Chong L, Liu Y, Liu P, et al. Nuciferine inhibits LPS-induced inflammatory response in BV2 cells by activating PPAR- $\gamma$. International immunopharmacology . 2018 Oct;63:9-13. 10.1016/j.intimp.2018.07.015

45. Wang C-Z, Zhang Y, Li X-D, Hu Y, Fang Z-G, Lin D-J, et al. PPAR $\gamma$ Agonist Suppresses TLR4 Expression and TNF- $\alpha$ Production in LPS Stimulated Monocyte Leukemia Cells. Cell Biochemistry and Biophysics . 2011 Jul 23;60(3):167-72. doi: 10.1007/s12013-010-9136-6. 